\title{
Effect of the Addition of Potassium or Lithium on the Columbite Precursor Microstructure
}

\author{
Alberto A. Cavalheiro ${ }^{\mathrm{a} *}$, Maria A. Zaghete ${ }^{\mathrm{a}}$, Carlos O. Paiva-Santos ${ }^{\mathrm{b}}$, José A. Varela \\ ${ }^{\mathrm{a}}$ LIEC and ${ }^{\mathrm{b}}$ Labcacc \\ Instituto de Química, UNESP \\ C.P. 355, 14801-970 Araraquara - SP, Brazil
}

Received: July 7, 2000; Revised: July 6, 2001

\begin{abstract}
Pechini method has been used to synthesize MN powders with stoichiometric control. By this method, $\mathrm{K}$ and Li-doped $\mathrm{MN}$ in the range from 0.1 to $5.0 \mathrm{~mol} \%$ of dopants have been obtained at relatively lower temperatures than it is possible with the conventional mixture of oxides. The results from BET analysis indicated that the doped powders have lower surface area and the attrition milling promotes an increase in surface area values for all powders. Rietveld method was used to calculate the mean crystallite size and the microstrain in the crystal. With additions of up to $5.0 \mathrm{~mol} \%$ of $\mathrm{K}$ or $2.0 \mathrm{~mol} \%$ of $\mathrm{Li}$, it is possible to obtain $\mathrm{MN}$ as a solid solution. Both dopants change the cell parameters of the columbite phase crystal, reduce the microstrain, and increase the main crystallite size. The analysis of results from SEM indicates that powders prepared with addition of dopants are more agglomerate than pure PMN powder.
\end{abstract}

Keywords: ceramic, columbite, PMN, Pechini and Rietveld method

\section{Introduction}

The Lead and Magnesium Niobate (PMN) is an excellent relaxor ferroelectric and it exhibits strong electrostrictive behavior. It can be used in the multi layer capacitors production due to its properties, like $\mathrm{K}_{\mathrm{m}}>20.000, \mathrm{~T}_{\mathrm{m}}=-15^{\circ} \mathrm{C}$, and low temperature of sintering $\left(\sim 1000^{\circ} \mathrm{C}\right)$. PMN possesses perovskite structure type $\mathrm{A}(\mathrm{B},, \mathrm{B}$ ' $) \mathrm{O}_{3}$ and it is pseudo-cubic in temperatures near to room temperature $\left(>\mathrm{T}_{\mathrm{m}}\right)$.

The process control of the micro and macro structure is essential to obtaining the reproducibility. The production of polycrystalline ceramics by chemical processes requests a special attention to the transformation and phase control and to the microstructural characteristics. Chemical processes offer many advantages such as purity, homogeneity, size control and particle shape. Stoichiometric control is fundamental in obtaining good properties and it is possible by using aqueous solutions synthesis. The increase in the dielectric constant can be also attributed to an increase in the grain size of the perovskite phase $\mathrm{e}^{1,2}$.

Columbite route involves two steps; in the first one the reaction between $\mathrm{MgO}$ and $\mathrm{Nb}_{2} \mathrm{O}_{5}$ occurs, resulting in a crystalline phase with composition $\mathrm{MgNb}_{2} \mathrm{O}_{6}$ and orthorhombic structures (columbite). In the second one it is developed the reaction between the columbite and $\mathrm{PbO}$ resulting in a $\mathrm{PMN}$ perovskite phase $\mathrm{Pb}\left(\mathrm{Mg}_{1 / 3} \mathrm{Nb}_{2 / 3}\right) \mathrm{O}_{3}$ close to $100 \%$. The direct correlation between $\mathrm{MgO}$ and the phases of the binary system $\mathrm{PbO}-\mathrm{Nb}_{2} \mathrm{O}_{5}$ influences on the amount of perovskite phase $^{3-5}$.

The Pechini method involves the cations chelation by hidroxi-carboxilic acids and the esterification with poly-alcohol. It is a new way of obtaining complex material with high specific surface area and high crystallinity at low temperatures and short times. The doping and reproducibility in ceramics with complex structures and involving many cations can be facilitated using Pechini method, which is an adequate method for detailed investigations of materials that require a rigorous phase control. Besides that, this process is extremely easy and cheap ${ }^{6-9}$.

Dielectric constant can be increased and $\mathrm{T}_{\mathrm{m}}$ can be moved at near room temperature by using several additives. These alterations optimize the characteristics of the capacitor and increase its applicability ${ }^{10,11}$. An example is $\mathrm{Na}_{2} \mathrm{O}$, which

*e-mail: albecava@bol.com.br 
increases the phase transformation difusivity and minimizes the intensities of X-ray diffraction peaks related to the superstructure. The occurrence of $\mathrm{Na}{ }^{\mathrm{Mg}}$ sites charged negatively generates an increase of the microcompositional fluctuation, simultaneous to the increase in the growth inhibition of the microdomains. Consequently, it happens the formation of oxygen vacancies (Vö) due to the ionic compensation. All the elements of the alkaline family are electron donors when they replace higher valence cations ${ }^{12-15}$. Based on these characteristics, it was proposed the utilization of the $\mathrm{K}$ and $\mathrm{Li}$ as the dopants for PMN ceramic. On the other hand, the important point that can indicate these additives as very promising is the similarity of the properties of the $\mathrm{LiNbO}_{3}$ and $\mathrm{KNbO}_{3}$ with $\mathrm{PbTiO}_{3}$ and $\mathrm{BaTiO}_{3}$, respectively. These new dopants proposed for the PMN are originally ceramics with high value for $T_{c}$, high spontaneous polarization, perovskite structure and ferroelectric properties. This way, probably it will be possible to dislocate $\mathrm{T}_{\mathrm{m}}$ to temperatures near at room temperature or to stabilize the perovskite phase $^{16}$.

It is very important that the Columbite precursor has a single phase and high surface area to obtain a large amount of PMN perovskite phase in the powder. Consequently, it is necessary a good control in the doping process and synthesis conditions for obtaining a precursor with adequate characteristics $^{17}$.

\section{Experimental Procedure}

\subsection{Chemical Synthesis}

Niobium oxide (Sigma - 99.9\%), basic magnesium carbonate (C.Q. - 99.5\%), potassium biftalate (Vetec - 99.95\%) and lithium carbonate (Carlo Erba - 99.5\%) were used for the preparation of pure and doped columbite precursor powders. The addition of ethylene glycol in a metal citrate solution, keeping the temperature of the solution between 80 and $100{ }^{\circ} \mathrm{C}$, promoted esterification. Heating of the ester at $150-250{ }^{\circ} \mathrm{C}$ formed the polyester, which was calcined at
$400{ }^{\circ} \mathrm{C}$ for $2 \mathrm{~h}$. After that, the burned resin was grounded in agate mortar and calcined again in alumina crucibles at $900{ }^{\circ} \mathrm{C}$ for $2 \mathrm{~h}$ in a box furnace with a flow of air. Attrition milling in isopropyl alcohol promoted the breaking of the agglomerates formed during the calcination. A stem coated with an inert polymer and zirconia balls were used to mill the powder for $1.5 \mathrm{~h}$ at $400 \mathrm{rpm}^{18}$.

\subsection{Characterization Methods}

The powders obtained after the calcination and grinding were characterized by scanning electronic microscopy (Topcon SM-300), X-ray diffraction (Rigaku - Rotaflex, 50 $\mathrm{KV}$ and $100 \mathrm{~mA}, \mathrm{~K}_{\mathrm{Cu}}$ ) using step-scan with step of 0.02(2theta degrees) during $2 \mathrm{~s}$ each step. The surface areas were also determinated using a surface analyzer CG-2000 with adsorption of $\mathrm{N}_{2}$ and BET analysis method.

Structure refinement were performed using the Rietveld method $^{19,20}$ based on the generalization of the Young-Desai formalism ${ }^{21}$. This generalization includes the simultaneous contribution from Gauss and Lorentz in the peak profile and it is part of the DBWS-9807 software, used in the refinement ${ }^{20}$. This software is a new version modified by PaivaSantos ${ }^{22}$ to include a subroutine that calculates the crystallite size (S) and the microstrain $(\varepsilon)$. A printed list in the end of the cycles shows the refinement results.

\section{Results And Discussion}

The data from X-ray diffraction were used to identify the crystalline phases present in the columbite powders. The Rietveld method was used to verify the effect of the potassium or lithium addition in the crystalline structure of the columbite phase. A tungsten carbide (WC) standard was previously characterized by the Rietveld method. This material is highly crystalline and has crystallite size infinitely large with microstrain absence. This standard permits that the instrumental contributions can be calculated based on the variables difference values related to the sample and to

Table 1. Initial structures for the identified phases in the studied precursor powders.

\begin{tabular}{|c|c|c|c|c|c|}
\hline Structure & Cell parameters & Atom & $\mathrm{x}$ & $\mathrm{y}$ & Z \\
\hline $\begin{array}{c}\mathrm{MgNb}_{2} \mathrm{O}_{6} \\
\text { G.E.: } \mathbf{P} \mathbf{b} \mathbf{~ c ~ n} \\
\text { ICSD: } 201962 \\
\mathrm{Z}=4\end{array}$ & $\begin{array}{l}\mathrm{a}=14.266(0) \AA \\
\mathrm{b}=5.733(0) \AA \\
\mathrm{c}=5.049(0) \AA \\
\mathrm{V}=413.0 \AA^{3} \\
\mathrm{O} 2-\end{array}$ & $\begin{array}{c}* \mathrm{Fe} \mathrm{II+} \\
\mathrm{Nb} \mathrm{V+} \\
\text { O 2- } \\
\text { O 2- } \\
0.7560(2)\end{array}$ & $\begin{array}{c}0 \\
0.3389(2) \\
0.0963(2) \\
0.4189(2) \\
0.1236(5)\end{array}$ & $\begin{array}{l}0.3311(5) \\
0.3191(3) \\
0.1041(4) \\
0.1163(5) \\
0.0793(6)\end{array}$ & $\begin{array}{c}1 / 4 \\
0.2506(6) \\
0.0727(5) \\
0.0990(5)\end{array}$ \\
\hline $\begin{array}{c}\mathrm{LiNbO}_{3} \\
\text { G.E.: R } \mathbf{3} \mathbf{c ~ H} \\
\text { ICSD: } 28298\end{array}$ & $\begin{array}{l}\mathrm{a}=5.170(10) \AA \\
\mathrm{c}=13.870(10) \AA \\
\mathrm{V}=321.1 \AA^{3} \mathrm{Z}=6\end{array}$ & $\begin{array}{l}\mathrm{Li} \mathrm{I}+ \\
\mathrm{Nb} \mathrm{V+} \\
\mathrm{O} 2-\end{array}$ & $\begin{array}{c}0 \\
0 \\
0.0398(67)\end{array}$ & $\begin{array}{c}0 \\
0 \\
0.3238(89)\end{array}$ & $\begin{array}{c}0.2752(68) \\
0 \\
0.0656(15)\end{array}$ \\
\hline
\end{tabular}

* Mg substitutes Fe in Refined structure. 
the pattern crystal which permits the calculation of the main crystallite size and microstrain in the samples.

Table 1 show the initial atomic parameters of the proposed structures for the refinement. The Li phase was identified only in the $5.0 \mathrm{~mol} \% \mathrm{Li}$-doped $\mathrm{MN}$ sample. The range used for the refinement was from 28 to 120 (2-theta) for minimizing the background effect at low angles.

Figure 1 shows Rietveld graphic for the pure sample $(\mathrm{MN})$. On it are represented the observed curve that was obtained by X-ray diffraction (spotted curve) and the calculated curve (continuous lines). The residual curve and the positions of the peaks (marked by small blue bars) are shown below. The residual pattern shows that there is a good match of the calculated and observed patterns, noted by the small variation along the diffraction angle.

$\mathrm{R}_{\mathrm{P}}, \mathrm{R}_{\mathrm{WP}}, \mathrm{R}_{\mathrm{exp}}$ and $\mathrm{S}$ indexes obtained from refinement of the K-doped MN samples are in Table 2. The microstrain $\varepsilon$, the main crystallites size $S$, the unitary cell parameters $a, b$, $\mathrm{c}$, and the volume $\mathrm{V}$ to each sample, are also presented.

The $\mathrm{R}_{\mathrm{P}}$ index indicates the agreement between the structure model adopted and the real one. Values smaller than 7.0 are appropriate as final result. $\mathrm{R}_{\mathrm{WP}}$ index indicates the quality of the refinement and values smaller than 9.0 are

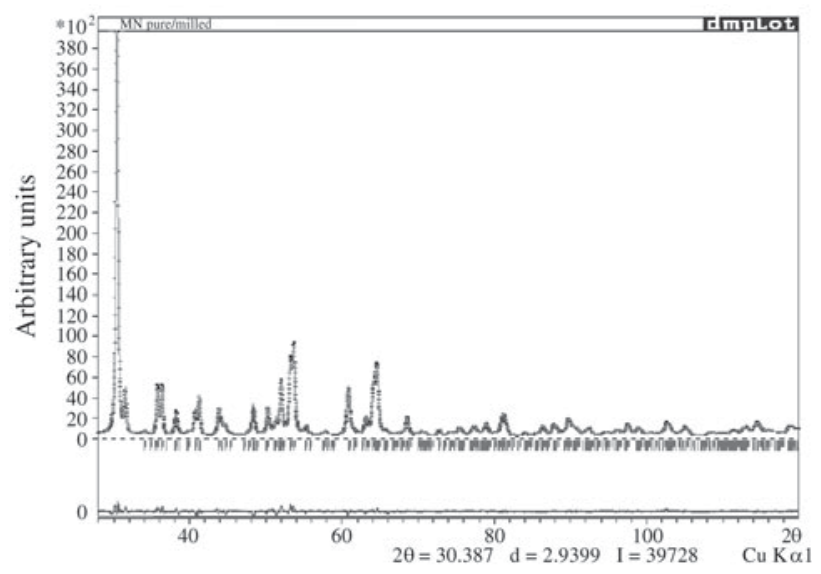

Figure 1. Rietveld graphic for pure MN sample. already acceptable. $\mathrm{R}_{\text {exp }}$ index is an approximate result of the inverse function of the diffraction peak intensity sum and it indicates the maximum value that the index $\mathrm{R}_{\mathrm{WP}}$ can assume. Patterns with high intensity peaks result very low values for the $\mathrm{R}_{\exp }$ index, like 2.0. However, a high value such as 8.0 for $\mathrm{R}_{\text {exp }}$, is obtained when patterns present low intensity peaks. Adjustment of the step during data collection or using the high-resolution equipment avoids obtaining high values for this index. $\mathrm{S}$ index is the ratio between $\mathrm{R}_{\mathrm{WP}}$ and $\mathrm{R}_{\text {exp }}$ indexes. Values from 1.5 to 3 are satisfactory.

All refinement indexes obtained for these samples can be considered good. $\mathrm{R}_{\mathrm{P}}$ and $\mathrm{R}_{\mathrm{WP}}$ indexes for the pure (MN) and $1.0 \mathrm{~mol} \%$ of $\mathrm{KNbO}_{3}$ (K10) samples are higher than those obtained for the other samples. However, only for the pure $\mathrm{MN}$ sample $\mathrm{S}$ index presented higher value. This fact is caused by the smallest value presented in $\mathrm{R}_{\exp }$ index for this sample. Unitary cell volume tends to increase with the $\mathrm{KNbO}_{3}$ addition, due the size of $\mathrm{K}$ ionic radius to be $1.33 \AA$, much larger than the radius of other cations in this system $(\mathrm{Nb}=0.67 \AA$ and $\mathrm{Mg}=0.65 \AA)$. The increase of $\mathrm{a}$ and $\mathrm{b}$ parameters causes an increase in cell volume, in spite of the decrease in c parameter. The K05 (0.5 mol\% of $\mathrm{KNbO}_{3}$ ) and K10 samples have shown values in disagreement with the expected increase. The cause of this abnormal behavior can be the small adaptation to the adopted model, which is not the best. It was confirmed by the largest value in $\mathrm{R}_{\mathrm{p}}$ index of these two samples, compared to the other ones, and the behavior of these two samples is similar to the pure MN sample. Main crystallite size tends to increase, because the big cation is causing the ordering of the phase. The K05 and K10 samples have parameter values out of the expected progression.

The results of the scanning electronic microscopy (Fig. 2) agree with the results obtained from the refinement. Micrograph $2 \mathrm{a}$ shows particles with sizes around $0.1 \mu \mathrm{m}$ without agglomerates for pure MN precursor. Micrograph $2 \mathrm{~b}$ shows agglomerates with sizes close to $6 \mathrm{~mm}$ formed by particles between 0.5 and $1.0 \mathrm{~mm}$ in size, for K50 samples. The increase in the main crystallite size, associated to the extinction of the microstrain, favors the particle growth and agglomeration. It is possible to notice that this agglomerate

Table 2. Refinement results for K-doped MN samples.

\begin{tabular}{l|cccc|cccccc}
\hline Sample & \multicolumn{5}{|c|}{ Refinement indexes } & \multicolumn{6}{c}{ Calculated crystalline parameters } \\
& $\mathrm{R}_{\mathrm{P}}$ & $\mathrm{R}_{\mathrm{wP}}$ & $\mathrm{R}_{\exp }$ & $\mathrm{S}$ & $\mathrm{a}(\AA)$ & $\mathrm{b}(\AA)$ & $\mathrm{c}(\AA)$ & $\mathrm{V}\left(\AA^{3}\right)$ & $\mathrm{S}(\AA)$ & $\varepsilon\left(10^{-2 \%}\right)$ \\
\hline MN & 5.25 & 6.97 & 2.88 & 2.41 & $14.1915(4)$ & $5.7014(1)$ & $5.0433(1)$ & $408.06(2)$ & 411 & 0.21 \\
$\mathrm{~K} 01$ & 4.90 & 6.61 & 3.04 & 2.17 & $14.1947(4)$ & $5.7027(1)$ & $5.0417(1)$ & $408.12(2)$ & 372 & 0.09 \\
$\mathrm{~K} 05$ & 5.18 & 6.88 & 3.03 & 2.26 & $14.1879(5)$ & $5.7002(2)$ & $5.0446(2)$ & $407.98(2)$ & 307 & 0.23 \\
K10 & 5.28 & 7.08 & 3.09 & 2.29 & $14.1888(5)$ & $5.7010(2)$ & $5.0455(2)$ & $408.13(2)$ & 326 & 0.19 \\
K20 & 4.83 & 6.51 & 2.83 & 2.30 & $14.1997(5)$ & $5.7046(2)$ & $5.0415(2)$ & $408.38(2)$ & 506 & 0 \\
K50 & 4.79 & 6.55 & 2.93 & 2.23 & $14.2054(3)$ & $5.7056(1)$ & $5.0411(1)$ & $408.58(1)$ & 554 & 0 \\
\hline
\end{tabular}



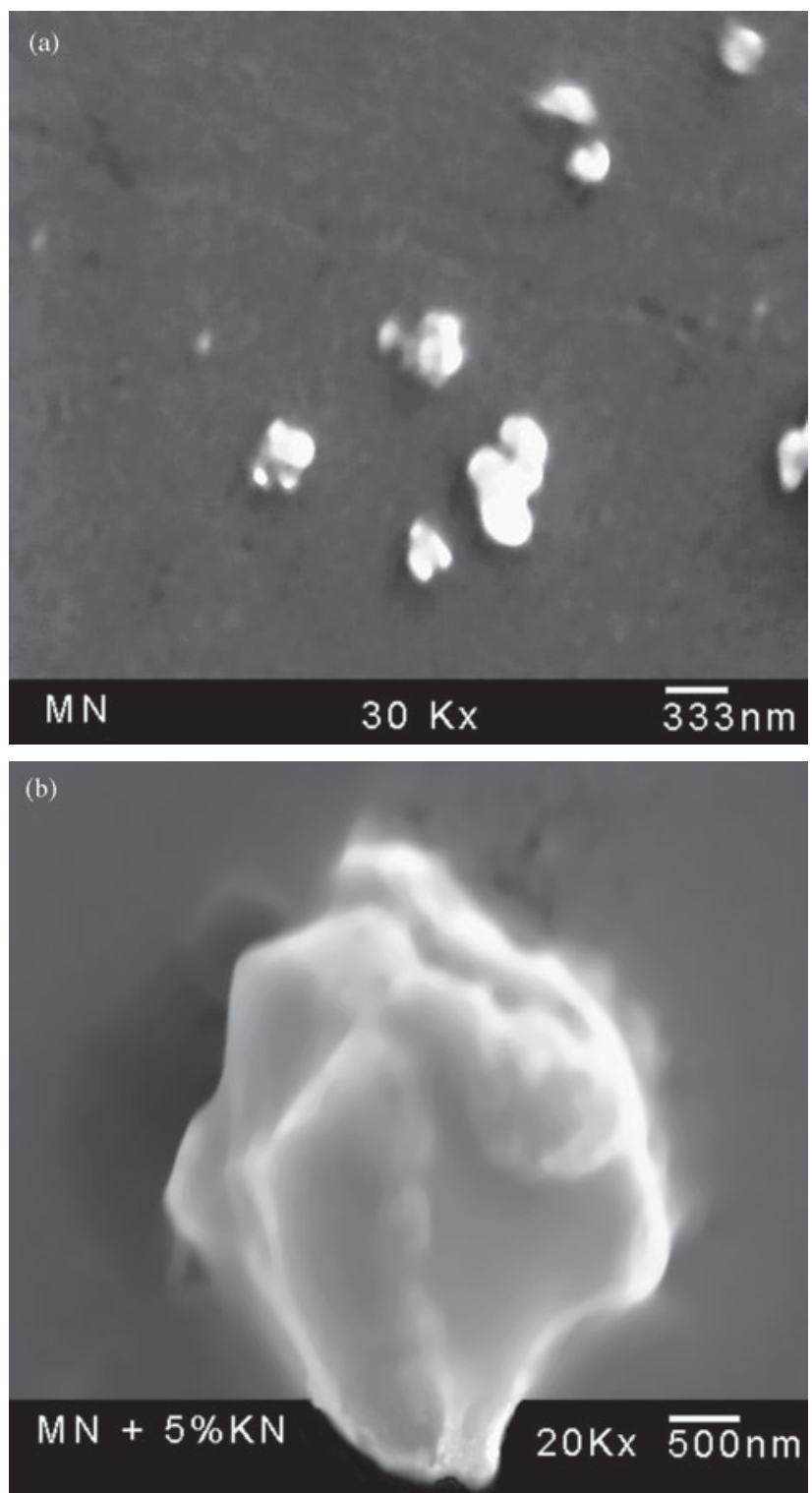

Figure 2. Scanning Electronic Micrographs for: a) MN and b) K50 samples. presents sintered particles showing that grinding was not efficient to promote its fracture.

The addition of $\mathrm{LiNbO}_{3}$ in $\mathrm{MgNb}_{2} \mathrm{O}_{6}$ presented very similar results to the ones obtained with the addition of $\mathrm{K}$. Changes in the behavior are observed for the dopant concentration of $5.0 \mathrm{~mol} \%$ in Li-doped MN sample (L50) in which it is possible to identify a second phase. Rhombohedral Li phase was precipitated because the solid solution $\mathrm{MgNb}_{2} \mathrm{O}_{6}-\mathrm{LiNbO}_{3}$ was saturated by high additive concentration. Figure 3 shows Rietveld graphic for this sample. The small number for the Bragg indexes for this sample indicates a low crystalline system symmetry. Quantitative phase analysis showed that the Li concentration is close to $1.5 \mathrm{~mol} \%$. These results allow estimating that the columbite phase can dissolve up to $3.5 \mathrm{~mol} \%$ of $\mathrm{Li}$ in order to obtain a powder with single phase. When a secondary phase is present in the MN precursor, the amount of pyrochlore phase increases during the PMN synthesis ${ }^{23,24}$.

Table 3 shows the results of the refinement for Li-doped MN samples. The volume of the unitary cell increases as a

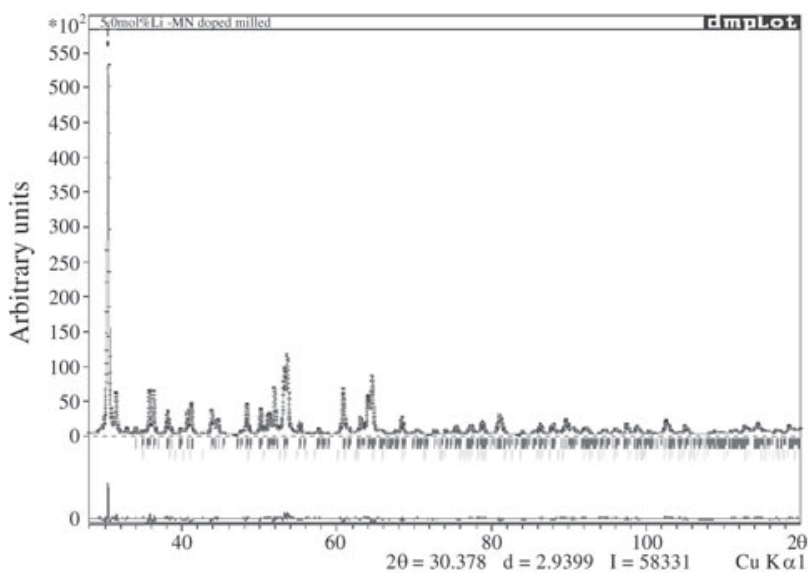

Figure 3. Rietveld graphic for L50 sample.

Table 3. Refinement results for Li-doped MN samples.

\begin{tabular}{|c|c|c|c|c|c|c|c|c|c|c|}
\hline \multirow[t]{2}{*}{ Sample } & \multicolumn{4}{|c|}{ Refinement indexes } & \multicolumn{6}{|c|}{ Calculated crystalline parameters } \\
\hline & $\mathrm{R}_{\mathrm{P}}$ & $\mathrm{R}_{\mathrm{WP}}$ & $\mathrm{R}_{\text {exp }}$ & $\mathrm{S}$ & a $(\AA)$ & b $(\AA)$ & c $(\AA)$ & $\mathrm{V}\left(\AA^{3}\right)$ & $S(\AA)$ & $\varepsilon\left(10^{-2} \%\right)$ \\
\hline MN & 5.25 & 6.97 & 2.88 & 2.41 & $14.1915(4)$ & $5.7014(1)$ & $5.0433(1)$ & $408.06(2)$ & 411 & 0.21 \\
\hline L01 & 6.06 & 7.97 & 4.98 & 1.59 & $14.1957(4)$ & $5.7025(1)$ & $5.0405(1)$ & 408.04(2) & 512 & 0.22 \\
\hline L05 & 4.98 & 6.51 & 2.87 & 2.26 & 14.1947(3) & $5.7024(1)$ & $5.0412(1)$ & $408.05(2)$ & 443 & 0.20 \\
\hline L10 & 4.90 & 6.71 & 2.93 & 2.28 & $14.1978(3)$ & $5.7035(1)$ & $5.0411(1)$ & $408.21(2)$ & 509 & 0.14 \\
\hline L20 & 4.68 & 6.47 & 2.99 & 2.16 & $14.2032(3)$ & $5.7054(1)$ & $5.0402(1)$ & 408.44(1) & 561 & 0.07 \\
\hline \multirow[t]{2}{*}{ L50 } & 5.91 & 7.67 & 2.88 & 2.66 & 14.2081(3) & $5.7061(1)$ & $5.0386(1)$ & $408.49(1)$ & 717 & 0 \\
\hline & \multicolumn{4}{|c|}{$1.5 \mathrm{~mol} \%$ of $\mathrm{LiNbO}_{3}^{*}$} & $5.159(3)$ & $5.1701(9)$ & $13.874(6)$ & $320.7(2)$ & 0 & 0.61 \\
\hline
\end{tabular}

* Phase present in L50 sample only. 
function of the additive concentration, due to the variation of the same parameters observed in the K-doped MN samples. The S index for L01 sample is very low when compared to the values obtained for other samples and it is due to the high $R_{\exp }$ index value. In consequence, $R_{w P}$ and $R_{P}$ indexes presented the highest values. When more than 1.0 mol\% of $\mathrm{Li}$ is added, the value of the microstrain is reduced dramatically, reaching the null value for L50 sample. Main crystallite size value for this sample is larger than the one for the sample with same concentration in K-doped MN samples. Note that lithium has a more accentuated effect on the crystallinity of the columbite phase than potassium. The phase identified as $\mathrm{LiNbO}_{3}$ presented high microstrain value and crystallite size infinitely small. This result indicates that this phase did not develope a good crystallization during the calcination.

Figure 4 show scanning electronic micrographs for $1.0 \mathrm{~mol} \%$ (L10) and $5.0 \mathrm{~mol} \%$ (L50) Li-doped MN samples. The micrograph of L10 sample (Fig. 4a) clearly shows some agglomerated particles, but these particles have not grown in size. The particles have size near to $0.1 \mu \mathrm{m}$, like the pure MN sample, and have spherical shape. In the Fig. 4b, L50 sample shows big and strong agglomerate, with sintered and grown particles. The size of these particles is close to $0.5 \mu \mathrm{m}$ and they seem to present elongated shape. Similar to the K-doped MN sample at the same concentration, this kind of agglomerate will not be easily broken either.

Table 4 shows specific surface area values for the calcined powder before and after milling. The results for powders before milling show different behavior for depending on the dopants. The K-doped MN samples present similar values for all concentrations, except to K50, that shows $\sim 50 \%$ less. This confirms the results observed by SEM analysis (Fig. 2), in which the sample K50 shows to be the most agglomerated.

For the Li-doped samples the data show that the surface area is directly influenced by the addition of the dopants. When the dopants concentration is $5.0 \mathrm{~mol} \%$, the value is
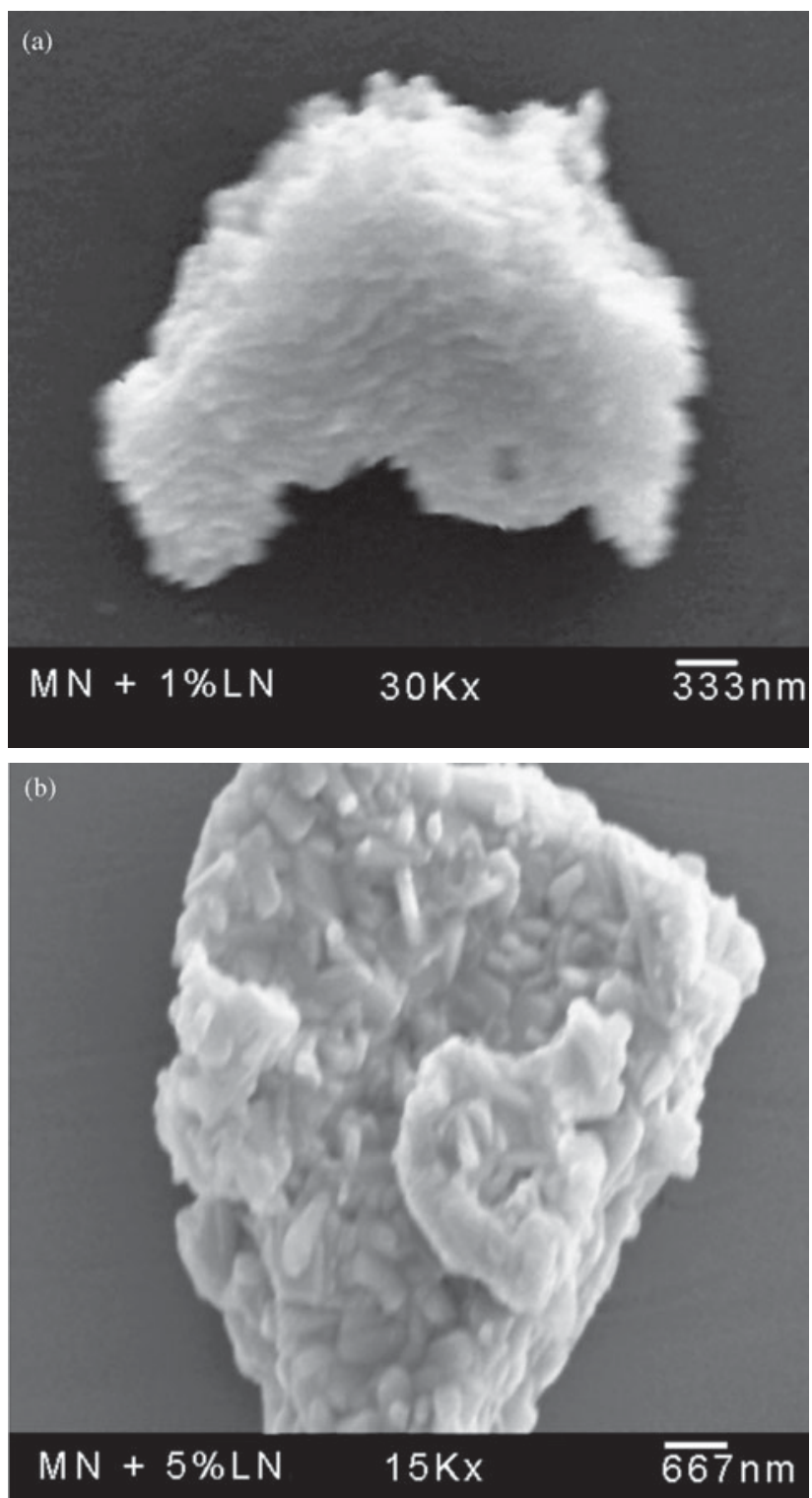

Figure 4. Scanning Electronic Micrographs for Li-doped MN samples in concentration of: a) $1.0 \mathrm{~mol} \%$ and b) $5.0 \mathrm{~mol} \%$.

Table 4. Surface area* for columbite precursor samples.

\begin{tabular}{|c|c|c|c|c|}
\hline \multirow{2}{*}{$\begin{array}{l}\text { Dopant } \\
(\mathrm{mol} \%)\end{array}$} & \multicolumn{2}{|c|}{ Calcined sample } & \multicolumn{2}{|c|}{ Milled sample } \\
\hline & K-doped MN & Li-doped MN & K-doped MN & Li-doped MN \\
\hline $0 * *$ & \multicolumn{2}{|c|}{12.1} & \multicolumn{2}{|c|}{17.0} \\
\hline 0.1 & 10.5 & 10.5 & 16.0 & 14.6 \\
\hline 0.5 & 10.7 & 10.2 & 17.7 & 13.8 \\
\hline 1.0 & 10.3 & 8.7 & 16.6 & 12.8 \\
\hline 2.0 & 10.1 & 6.2 & 16.3 & 10.3 \\
\hline 5.0 & 5.9 & 1.6 & 12.0 & 6.4 \\
\hline
\end{tabular}

* Values in $\mathrm{m}^{2} / \mathrm{g}$. ** Pure sample. 
too much reduced, to like $1.6 \mathrm{~m}^{2} / \mathrm{g}$. On the micrograph (Fig. 4) it is possible to confirm these results, observing the big agglomerate of the sintered particles.

After milling in attrition mill, the K-doped MN samples had the specific surface area value increased in around $60 \%$, up to the concentration of $2.0 \mathrm{~mol} \%$. For the $5.0 \mathrm{~mol} \%$ K-doped sample, the increase was of $100 \%$, due the great number of agglomerates broken during milling. Besides, after milling, the value was only $25 \%$ smaller than the ones for the other samples of this system, because the grinding process was enough to break the particles strongly agglomerated.

For Li-doped MN samples, the specific surface area values decreased with the increase in the amount of dopant, reaching $6.4 \mathrm{~m}^{2} / \mathrm{g}$ for the L50 sample. Besides that, the efficiency in the grinding process increases, from $40 \%$ (L01) up to $300 \%$ (L50). Li-doped MN samples have smaller specific surface area than the K-doped one, for all the additive concentrations. This seems to be related to the partial sinterization of the particles during the calcination of the powders.

The characterization techniques used to analyze the doping effect in columbite precursor allowed to obtain coherent results. The samples with low concentration of dopants presented larger deviations than the ones with high concentrations due the greater influence of the experimental parameters variation intrinsic to the synthesis process.

\section{Conclusions}

Pechini's method has been an adequate method to obtaining of doped MN samples with controlled stoichiometry. It is also possible to verify the influence of dopants in the reactivity of the $\mathrm{MN}$ powders. In addition, it permits to obtain doped MN powders at lower temperatures than it is possible with the conventional mixture of oxides. With additions of up to $5.0 \mathrm{~mol} \%$ of $\mathrm{K}$ or $2.0 \mathrm{~mol} \%$ of $\mathrm{Li}$, it is possible to obtain the columbite precursor as a solid solution. Both dopants change the cell parameters in the columbite phase crystal, reduce the microstrain, and increase the main crystallite size. The reactivity of the powders is only significantly too lower for doped samples with $5.0 \mathrm{~mol} \%$ of the additives.

\section{Acknowledgements}

The authors thank FAPESP for the financial support.

\section{References}

1. Gupta, S.M.; Kulkarni, A.R. J. Eur. Ceram. Soc., v. 4, n. 16, p. 473-480, 1996.

2. Van Vlack, L.H. Princípios de Ciência dos Materiais. Edgard Blücher. S.Paulo, 1970.

3. Swartz, S.L.; Shrout, T.R. Mat. Res. Bull., v. 17, p. 12451250, 1982.

4. Lejeune, M.; Boilot, J.P. Ceram. Intern., v. 2, n. 8, p. 119-122, 1982.

5. Lejeune, M.; Boilot, J.P.Ceram. Intern., v. 3, n. 8, p. 99103, 1982.

6. Anderson, H.V.; Pennel, M.J.; Guha, J.P. Advances in Ceramics., v. 21, p. 91-98, 1987.

7. Pechini, M.P. U.S. Patent \# 3.330.697, July 11, 1967.

8. Lessing, P.A. Ceram. Bull., v. 5, n. 69, p. 1002-1007, 1989.

9. Camargo, E.R.; Longo, E.; Leite. E.R. J. Sol-Gel Sci. and Tech., v. 2, n. 7, p. 111-121, 2000.

10. Landin, S.M.; Schulze, W.A. J. Am. Ceram. Soc., v. 73, n. 4, p. 909-912, 1990.

11. Lin, L.J.; Wu, T.B. J. Am. Ceram. Soc., v. 73, n. 5, p. 1253-1256, 1990.

12. Lee, K.-M.; Jang, H.M. J. Mater. Res., v. 12, n. 6, p. 1614-1624, 1997.

13. Zhang, Q.M.; You, H.; Muivihill, M.L.; Jang, S.J. Solid State Comm., v. 8, n. 97, p.693-698, 1996.

14. Vakhrushev, S.; Nabereznov, A.; Sinha, S.K.; Feng, Y.P.; Egami, T. J. Phys. Chem. Solid v., 57, n. 10, p.15171523, 1996.

15. Wang, Y.; Gui, Z.; Chan, Y.C.; Read, L.I.; Zhang, X.J. Mater. Sci., v. 7, p. 1353-1358, 1996.

16. Kittel, C. Introduction to Solid State Physics. John Wiley $\&$ Sons, Inc. New York, $6^{\text {th }}$ edition, 1986.

17. Horowitz. H. J. Am. Ceram. Soc., v. 5, n. 71, p. 250251, 1988.

18. Cavalheiro, A.A.; Zaghete, M.A.; Varela, J.A. Cerâmica, v. 45, n. 292/293, p.56-60, 1999.

19. Rietveld, H.M. J. Appl. Cryst., v. 10, p. 65-71, 1969.

20. Young, R.A.; Larson, A.C.; Paiva-Santos, C.O. User's Guide to Program DBWS-9807 for Rietveld Analysis of X-ray and Neutron Powder Diffraction Patterns. School of Physics - Georgia Inst. of Technology. Atlanta, GA30332, 1998.

21. Young, R.A.; Desai, P. Archiwum Nauki Materialach., p. 71-90, 1989.

22. Paiva-Santos, C.O.; Gouveia, H.; Las, W.C.; Varela, J.A. 18을 Materials Structure., v .6, n. 2, p. 1-4, 1999.

23. Kim, N.-K. Mater. Lett., v. 32, p. 127-130, 1997.

24. Cavalheiro, A.A.; Zaghete, M.A.; Varela J.A. Cerâmica, v. 45, n. 296, p. 188-192, 1999. 